\title{
Persistence and Prognostic Implications of Orthostatic Hypotension in Older Individuals with Mild-to-Moderate Dementia
}

\author{
Hogne Soennesyn Ingvild Dalen Dag Aarsland \\ Centre for Age-Related Medicine, Stavanger University Hospital, Stavanger, Norway
}

\section{Key Words}

Dementia · Orthostatic hypotension · Survival analysis

\begin{abstract}
Aim: To study the course and prognostic implications of orthostatic hypotension $(\mathrm{OH})$ in older individuals with mild-to-moderate dementia. Methods: Referrals to outpatient clinics specialising in old age psychiatry and geriatric medicine in the counties of Rogaland and Hordaland in western Norway with a first-time diagnosis of mild dementia were consecutively asked for inclusion. A total of 211 participants underwent a comprehensive baseline assessment with annual follow-ups. Patients with $\mathrm{OH}$ at both baseline and the 1-year follow-up were classified as having persistent $\mathrm{OH}$. Outcome measures were the Mini-Mental State Examination (MMSE), the Clinical Dementia Rating sum of boxes (CDR-SB), and time to death. Results: From baseline to the 4-year follow-up, 30-45\% of the participants had $\mathrm{OH}$ at each follow-up. In multivariable analysis, persistent $\mathrm{OH}$ was not significantly associated with either the longitudinal course of MMSE or CDR-SB scores or survival. Conclusions: $\mathrm{OH}$ was moderately prevalent over 4 years in older individuals with mild dementia, and persistent $\mathrm{OH}$ did not predict either cognitive or functional decline or survival.

(c) 2014 S. Karger AG, Basel
\end{abstract}

\section{Introduction}

Orthostatic hypotension $(\mathrm{OH})[1,2]$, corresponding to the syndrome known as 'classical $\mathrm{OH}^{\prime}$ [3], is commonly diagnosed in older individuals [4], including those with dementia [5-7]. Generally, as well as in a single older patient, $\mathrm{OH}$ may have several causes, including agerelated changes in the cardiovascular and autonomic nervous systems [8], autonomic dysfunction (which is common in neurodegenerative dementias) [9], medication [10], and acute illness with a reduction in intravascular volume [8]. $\mathrm{OH}$ is associated with falls [11], 
Soennesyn et al.: Persistence and Prognostic Implications of Orthostatic Hypotension in Older Individuals with Mild-to-Moderate Dementia

coronary heart disease, and mortality [12]. It also has been associated cross-sectionally with cognitive impairment in the elderly $[13,14]$.

However, only few studies have explored the potential longitudinal implications of $\mathrm{OH}$ with regard to cognitive function in older individuals with mild dementia. Viramo et al. [15] found no longitudinal association between $\mathrm{OH}$ and cognition over a period of 2.5 years; cognitive decline was predicted only by old age and a low level of formal education. Likewise, not much is known with respect to the potential implications of $\mathrm{OH}$ for activities of daily living (ADL), although a previous cross-sectional study found that higher autonomic symptom scores and postural dizziness in non-Alzheimer's dementias were associated with poorer outcomes in ADL [16]. Concerning the potential impact of $\mathrm{OH}$ on survival in dementia, Stubendorff et al. [17] recently found that patients with dementia with Lewy bodies (DLB) and Parkinson's disease with dementia (PDD) with persistent $\mathrm{OH}$ over a period of up to 6 months had a significantly shorter survival than those without persistent $\mathrm{OH}$.

$\mathrm{OH}$ is potentially treatable $[18,19]$, meaning that its possibly negative impact on cognitive function and ADL might be alleviated. Notably, in the majority of dementia patients with $\mathrm{OH}$, classical symptoms such as dizziness or unsteadiness seem to be absent [20].

The reproducibility of $\mathrm{OH}$ on repeated measurements has been studied in various populations [21-25], with inconsistent results [26]. It has not, to our knowledge, been established whether, and to what extent, $\mathrm{OH}$ is persistent over the longer term in older individuals with dementia. In a previous study, we reported the cross-sectional prevalence of $\mathrm{OH}$ in individuals with mild dementia [7]. Here, we wanted to study the longitudinal course of $\mathrm{OH}$ in the stages of mild-to-moderate dementia and to investigate the hypothesis that patients with persistent $\mathrm{OH}$ have a more rapid cognitive and functional decline as well as a shorter survival than those without $\mathrm{OH}$.

\section{Subjects and Methods}

\section{Ethics Statement}

The study was approved by the Regional Committee for Medical and Health Research Ethics (REC West) and the Norwegian authorities for the collection of medical data. Each patient provided written consent to participate in the study after the procedures had been explained in detail to him/her and a caregiver, usually the spouse or an offspring.

\section{Subjects}

From March 2005 to April 2007, all referrals to the 5 outpatient clinics specialising in old age psychiatry and geriatric medicine in the counties of Rogaland (Stavanger and Haugesund) and Hordaland (Bergen) in western Norway were screened for patients with a first-time diagnosis of mild dementia (according to the DSM-IV [27]) having a Mini-Mental State Examination (MMSE) [28] score of 20 or more (upper limit: 30). Additionally, the 3 neurology outpatient clinics in the same area were contacted, and they agreed to refer new cases with mild dementia to one of the participating centres. The patients and caregivers were first seen by a study clinician, who performed a structured clinical interview. The comprehensive assessment procedure included a detailed history, using a semi-structured interview, a clinical evaluation (including physical, psychiatric, neurological, and neuropsychological examinations), and routine blood tests.

\section{Procedures}

The patients were followed up annually with the same assessment battery for the first 2 years, thereafter with a simplified test battery. 


\section{Dementia Diagnosis}

Diagnoses were made after a detailed evaluation, as previously described [29], including the use of standardised clinical assessments of psychiatric symptoms, parkinsonism, and cognitive fluctuations as well as brain magnetic resonance imaging (MRI) [30] and blood tests. The diagnoses of Alzheimer's disease (AD), DLB, PDD, and vascular dementia (VaD) were made according to consensus criteria [31-34], and those of alcoholic dementia and frontotemporal dementia (FTD) according to the DSM-IV criteria and the Lund-Manchester criteria [35], respectively. Patients with acute delirium or terminal illness, those recently diagnosed with a major somatic disease, and those with previous bipolar or psychotic disorder were excluded from the study. In the present study, the patients having DLB and those having PDD were combined into one group (Lewy body dementia, LBD) because these conditions have several biological and clinical similarities [32, 36].

\section{Clinical Assessment}

The MMSE was used as a measure of cognitive function. The Clinical Dementia Rating sum of boxes [37] (CDR-SB) was employed as a composite measure of cognitive and general function [38, 39]. For the assessment of physical comorbidity, we employed the Cumulative Illness Rating Scale (CIRS). This scale measures the chronic medical illness burden while also taking into account the severity of a chronic disease. It was scored by an experienced geriatrician in accordance with the guidelines [40]. Depression was assessed using the Montgomery-Åsberg Depression Rating Scale (MADRS) [41, 42].

MR images were rated visually for the severity of white matter hyperintensities (WMH), using the Scheltens scale [43], by an experienced rater blinded to the clinical data. For further details, see Soennesyn et al. [30]. In the present study, we used the Scheltens total WMH score only. For more details on the selection, diagnostic, and assessment procedures, see Aarsland et al. [29].

\section{Survival and Mortality}

We registered all deaths from study inclusion until October 1, 2012.

\section{Blood Pressure Measurements and Definitions of $\mathrm{OH}$}

Blood pressures were measured using an analogue sphygmomanometer, once with the subject in the supine $(n=123)$ or sitting position $(n=83 ; n=5$ unknown whether supine or sitting) and then once within 3 min after standing up. If more than 1 standing measurement had been made for a given subject ( $\mathrm{n}=14$ at the 1-year follow-up; $\mathrm{n}=1$ at the 2-year followup), the lowest systolic and diastolic blood pressure values were used for the diagnosis of $\mathrm{OH}[12]$.

$\mathrm{OH}$ was defined according to the consensus criteria $[1,2]$ as a reduction in systolic blood pressure of at least $20 \mathrm{~mm} \mathrm{Hg}$, or in diastolic blood pressure of at least $10 \mathrm{~mm} \mathrm{Hg}$, within 3 min of standing. 'OH+' ('persistent' $\mathrm{OH}$ ) was defined as having $\mathrm{OH}$ both at baseline and at the 1-year follow-up, and ' $\mathrm{OH}-$ ' ('never' $\mathrm{OH}$ ) as not having $\mathrm{OH}$ at either of these examinations. The assessments took place during normal office hours (i.e. 8 a.m. to 4 p.m.).

\section{Statistical Analyses}

Statistical analyses were performed using IBM SPSS Statistics version 20 and R version 2.15.2. The baseline characteristics are presented as quartiles (continuous variables) and proportions (dichotomous variables). The proportions of patients with $\mathrm{OH}$ at each assessment are presented with continuity-corrected 95\% confidence intervals (95\% CI; http:// vassarstats.net/). The clinical outcome measure scores (MMSE and CDR-SB) in those with and those without $\mathrm{OH}$ at each assessment were compared using independent-samples t tests. 
Soennesyn et al.: Persistence and Prognostic Implications of Orthostatic Hypotension in Older Individuals with Mild-to-Moderate Dementia

Table 1. Baseline clinical characteristics of the patients with $\mathrm{OH}$ measurements at both baseline and the 1-year follow-up and of those not having these two measurements

\begin{tabular}{|c|c|c|c|}
\hline & \multicolumn{2}{|c|}{$\begin{array}{l}\text { OH measurements both at baseline } \\
\text { and 1-year follow-up }\end{array}$} & \multirow[t]{2}{*}{$\begin{array}{l}\text { Missing data } \\
(\mathrm{n}=211)\end{array}$} \\
\hline & yes $(n=133)$ & no $(n=78)$ & \\
\hline Age, years & $77.2(71.0-82.0)$ & $76.5(70.0-80.6)$ & 0 \\
\hline Women, n (\%) & $79(59)$ & $45(58)$ & 0 \\
\hline Education, years & $9(8-12)$ & $8(7-10)$ & 7 \\
\hline MMSE score & $24.0(22.0-26.0)$ & $23.0(21.8-25.3)$ & 2 \\
\hline CDR-SB score & $4.5(3.5-6.4)$ & $5.5(3.5-8.0)$ & 16 \\
\hline $\mathrm{AD}, \mathrm{n}(\%)$ & $91(68)$ & $47(60)$ & 0 \\
\hline DLB/PDD, n (\%) & $28(21)$ & $26(33)$ & 0 \\
\hline VaD, n (\%) & $8(6)$ & $3(4)$ & 0 \\
\hline Other dementias (FTD, Alc.), n (\%) & $6(5)$ & $2(3)$ & 0 \\
\hline MADRS total score ${ }^{a}$ & $6(3-13)$ & $7(4-11)$ & 1 \\
\hline Using antidementia medications, $\mathrm{n}(\%)^{\mathrm{b}}$ & $52(39)$ & $26(34)$ & 2 \\
\hline Smoker (former/current), n (\%) & $61(47)$ & $34(47)$ & 8 \\
\hline CIRS score ${ }^{c}$ & $6(4-7)$ & $6(4-8)$ & 3 \\
\hline Cardiovascular disease, $\mathrm{n}(\%)^{\mathrm{d}}$ & $41(33)$ & $25(35)$ & 14 \\
\hline
\end{tabular}

Values denote medians with IQR in parentheses unless specified otherwise. Alc. = Alcoholic dementia.

${ }^{\mathrm{a}}$ Range: $0-60 .{ }^{\mathrm{b}}$ Acetylcholinesterase inhibitor or memantine. ${ }^{\mathrm{c}}$ Range: 0 (no impairment) to 52 (extremely severe impairment). ${ }^{\mathrm{d}}$ History of stroke or coronary heart disease.

The survival analysis was conducted with Kaplan-Meier plots and Cox proportional hazards modelling in SPSS. As explanatory variables, we used $\mathrm{OH}+$ (yes/no) together with various combinations of potential confounders (see below). The presence of time-dependent effects of $\mathrm{OH}$ was tested by means of the TIME PROGRAM command.

Analyses of the longitudinal outcomes were performed with generalised estimating equations (GEE) in SPSS, in which $\mathrm{OH}+(y e s / n o)$, time, and the interaction between $\mathrm{OH}+$ and time were entered as model effects, along with various combinations of potential confounders from baseline measurements: centre, age, sex, education (in years), smoking [44] (ever/ never), $\mathrm{AD}$ versus other dementia, dementia medication (acetylcholinesterase inhibitor or memantine - yes/no), CIRS score, cardiovascular disease (history of stroke or coronary heart disease - yes/no), MADRS score, and MMSE or CDR-SB score (the one that was not the dependent variable). Four modelling schemes were tried: (1) no adjustment, in which only terms involving $\mathrm{OH}+$ and/or time were included; (2) adjusting for age and sex; (3) adjusting for all available potential confounders, and (4) adjusting for the variables that were deemed important after a (manual) stepwise reduction of the model based on likelihood ratio tests (though keeping $\mathrm{OH}+$, time, the interaction $\mathrm{OH}+/$ time, sex, and age in the model). All the results were based on a robust estimation of unstructured correlation matrices.

As informative dropout due to death $[45,46]$ was suspected in this study, we also ran analyses which were intended to deal with this issue. The function 'joineR' in R [47] is based on a linear mixed model for the longitudinal outcome and a proportional hazards model for the survival outcome, which are linked through common random effects. The various models described above were fitted, allowing for various kinds of links between the random effects relating to the longitudinal outcome and the frailty relating to the survival outcome. The optimal structure of random effects for each combination of fixed effects was determined by 
Table 2. Point prevalence and persistence of $\mathrm{OH}$ from the previous examination among the patients evaluated (baseline to 4-year follow-up)

\begin{tabular}{llllll}
\hline & Baseline & $\begin{array}{l}\text { 1-year } \\
\text { follow-up }\end{array}$ & $\begin{array}{l}\text { 2-year } \\
\text { follow-up }\end{array}$ & $\begin{array}{l}\text { 3-year } \\
\text { follow-up }\end{array}$ & $\begin{array}{l}\text { 4-year } \\
\text { follow-up }\end{array}$ \\
\hline Point prevalence of OH & $\begin{array}{l}74 / 169 \\
(44 ; 36-52)\end{array}$ & $\begin{array}{l}51 / 163 \\
(31 ; 24-39)\end{array}$ & $\begin{array}{l}36 / 121 \\
(30 ; 22-39)\end{array}$ & $\begin{array}{l}50 / 112 \\
(45 ; 35-54)\end{array}$ & $\begin{array}{l}39 / 87 \\
(45 ; 34-56)\end{array}$ \\
\hline Persistence of OH & - & $\begin{array}{l}29 / 58 \\
(50 ; 37-63)\end{array}$ & $\begin{array}{l}15 / 34 \\
(44 ; 28-62)\end{array}$ & $\begin{array}{l}14 / 24 \\
(58 ; 37-77)\end{array}$ & $\begin{array}{l}14 / 28 \\
(50 ; 31-69)\end{array}$ \\
\hline
\end{tabular}

Values denote numbers with percentages and 95\% CI in parentheses.

the Akaike information criterion [48]. Normal-based confidence intervals and Wald $\chi^{2} p$ values for fixed and random effects were estimated by non-parametric (resampling) bootstrapping (200 bootstrap samples) [49]. Since the purpose of these joint models was to improve on the results for the longitudinal outcomes 'CDR-SB score' and 'MMSE score', we limited the covariates for the survival outcome to just $\mathrm{OH}+$ (yes/no), age, and sex.

The treatment of missing data amounted to excluding from each analysis the subjects with missing observations of the relevant variables (available case analysis), assuming noninformative missingness. The exception to this was the joint analyses, where the effects of dropouts due to death were accounted for implicitly in the models.

\section{Results}

Of the 211 patients available at baseline, $133 \mathrm{had} \mathrm{OH}$ measurements at both baseline and the 1-year follow-up. Patients with these two $\mathrm{OH}$ measurements had a somewhat longer education and higher cognitive performance than those not having these two measurements (table 1). Otherwise, the groups did not differ substantially with respect to the relevant baseline characteristics.

Of the 133 patients, between 21 and 44 were recruited from each of the 4 largest participating centres, but only 4 patients were recruited from the smallest, fifth centre. There were 91 patients with $A D$ and 28 having LBD. With respect to the variables in table 1, these groups differed significantly in terms of sex ( 69 vs. $43 \%$ women, $p=0.021$ ), MADRS score ( 5 vs. 12 , $\mathrm{p}=0.001$ ), use of antidementia medications (51 vs. $18 \%, \mathrm{p}=0.004)$, and CIRS total score (5.0 vs. $6.5, \mathrm{p}=0.003$ ).

A total of 94 of the 211 patients included at baseline did not complete the 4-year followup. Of these, 67 died prior to the expected 4-year follow-up time. Of the remaining 27 patients, 8 withdrew from the study, 1 moved, 6 were excluded for various reasons, and 12 missed the follow-up for unknown reasons.

\section{Course of $\mathrm{OH}$}

At each assessment, $\mathrm{OH}$ measurements were available for $75-86 \%$ of the participating patients. For the point prevalence and persistence of $\mathrm{OH}$ from the previous examination among those measured, see table 2 . Among the 85 patients with $\mathrm{OH}$ measurements at baseline, the 1-year follow-up, and the 2-year follow-up, 32 'never' had $\mathrm{OH}, 18 \mathrm{had} \mathrm{OH}$ once, 27 twice, and only 8 had $\mathrm{OH}$ at all 3 measurements. 
Fig. 1. $\mathrm{OH}$ classification flow

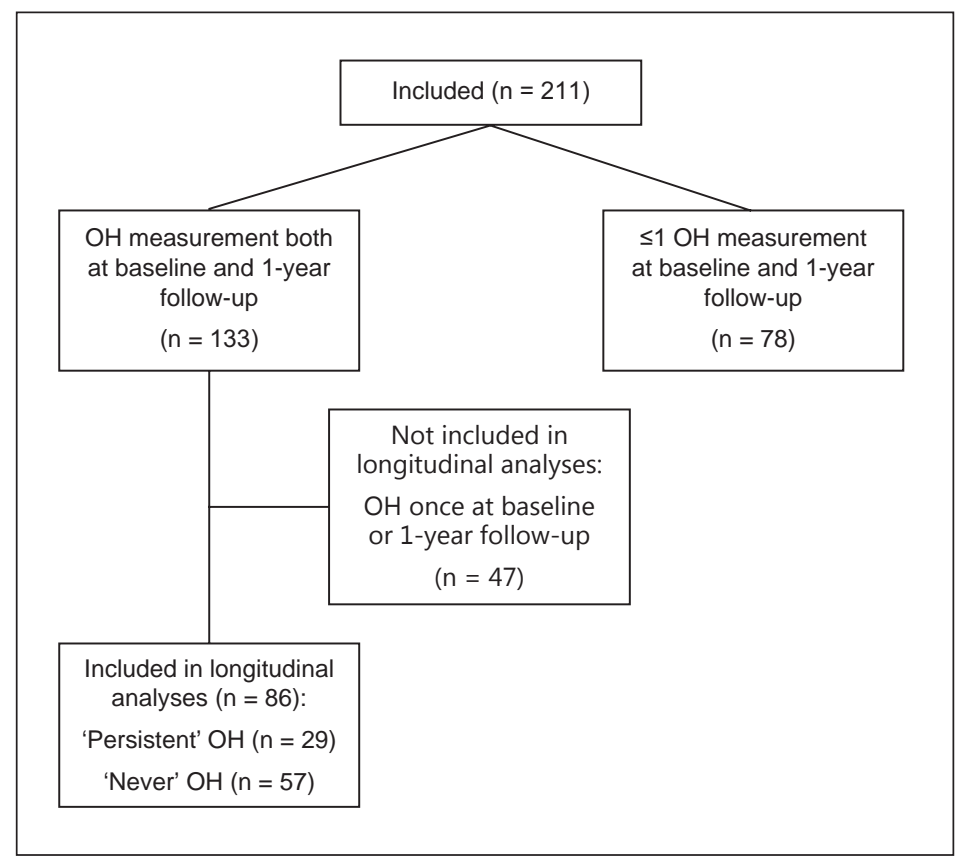
chart.

Of the 133 patients who had complete data on $\mathrm{OH}$ measurements at both baseline and the 1-year follow-up, 29 were $\mathrm{OH}$ positive on both occasions and were thus classified as 'persistent $\left.\mathrm{OH}^{\prime} \mathrm{OH}+\right)$, whereas 57 were $\mathrm{OH}$ negative on both occasions and were classified as 'never $\mathrm{OH}^{\prime}$ ( $\mathrm{OH}$-; fig. 1). There were no significant differences in mean non-standing systolic or diastolic blood pressure between those measured in the supine and those measured in the sitting position at baseline (data not shown). The general condition of the patients in these groups $(\mathrm{OH}+$ and $\mathrm{OH}-)$ at baseline did not differ significantly [good general condition (compared with average or bad): 93 vs. $85 \%, p=0.482$ ], and the median CIRS total score was 6.0 (potential maximum score: 52$)$ in both groups $(\mathrm{p}=0.491)$. There were no significant differences between the $\mathrm{OH}+$ and the $\mathrm{OH}$ - group with respect to history of hypertension (55 vs. $44 \%, p=0.437$ ), prevalence of diabetes mellitus type 1 or 2 (13 vs. $0 \%, p=0.090$ ), prevalence of kidney disease (median CIRS renal score 0 in both groups), use of at least 1 medication associated with $\mathrm{OH}$ (antianginals, antihypertensives, tricyclic antidepressants, paroxetine, MAO inhibitors, dopamine agonists, diazepam, dipyridamole, phenothiazines, clozapine, quetiapine, olanzapine, or haloperidol; 59 vs. $54 \%, \mathrm{p}=0.831$ ), use of antihypertensive medication (55 vs. $46 \%, \mathrm{p}=0.592$ ), or Scheltens total WMH score (median score: 11.5 vs. 14.0, $\mathrm{p}=0.525$ ). Baseline serum lipid values were available for only 3 of these patients.

\section{OH and Survival}

As of October 1, 2012, a total of 14 patients out of 29 (48\%) had died in the OH+ group, whereas 29 out of 57 (51\%) had died in the $\mathrm{OH}$ - group. A Kaplan-Meier plot with separate survival curves for each $\mathrm{OH}$ group is shown in figure 2 . As can be seen, the curves are very similar. The mean survival time in the OH- group was 5.7 years ( $95 \% \mathrm{CI}: 5.2-6.3$ ), and in the $\mathrm{OH}+$ group 5.8 years (95\% CI: 5.1-6.5); the corresponding median survival times were 6.8 and 6.2 years. A Cox regression model showed no significant effect of $\mathrm{OH}$ status (unadjusted $\mathrm{p}=0.999$ ). Adjusted for age and sex (both contributing significantly to the model), the estimated $\mathrm{HR}$ for $\mathrm{OH}+$ versus $\mathrm{OH}$ - was 0.83 (95\% CI: 0.44-1.57, $\mathrm{p}=0.562$ ). Adding other baseline variables to the model (smoking, CDR-SB score, MMSE score, CIRS score, cardiovascular 
Fig. 2. Observed survival for the $\mathrm{OH}+$ group (grey) and for the $\mathrm{OH}-$ group (black).

Fig. 3. Box plot of MMSE scores from baseline (BL) to 4-year follow-up (FU4). Light grey: patients with $\mathrm{OH}$ at each examination. Dark grey: patients without $\mathrm{OH}$ at each examination.
Soennesyn et al.: Persistence and Prognostic Implications of Orthostatic Hypotension in Older Individuals with Mild-to-Moderate Dementia
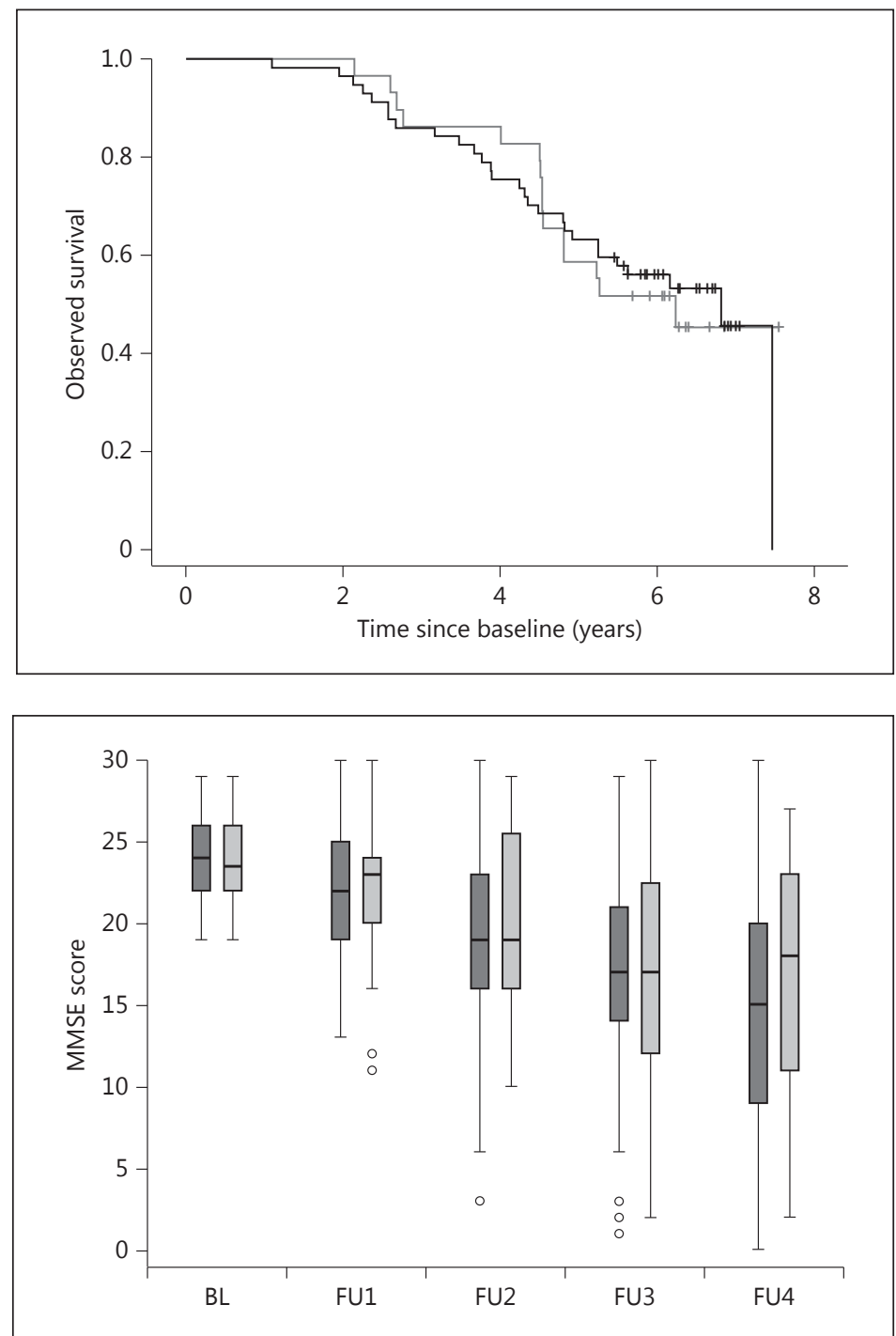

disease, $\mathrm{AD}$ vs. non-AD dementia, or centre) did not change the results substantially; neither did $\mathrm{OH}$ status interact statistically significantly with time in the tested models.

\section{$\mathrm{OH}$ and Function}

Cognitive and general function declined as expected, as was measured with the MMSE and the CDR-SB. At the 4-year follow-up, the median MMSE score was 15.0 (IQR: 10.0-22.8) and the median CDR-SB score 13.0 (IQR: 8.4-15.3) among those having two OH measurements from baseline to the 1-year follow-up. The corresponding values for those without two OH measurements were 15.5 (IQR: 8.0-20.0) and 13.0 (IQR: 10.0-15.5). There were no significant differences between those with and those without $\mathrm{OH}$ regarding MMSE scores (fig. 3) or CDR-SB scores (fig. 4) at baseline or at any of the follow-up examinations (all $t$ test $p$ values $\geq 0.093$ ).

In total, we had 349 observations of MMSE scores and 350 observations of CDR-SB scores for the 86 patients who were classified as either $\mathrm{OH}+$ or $\mathrm{OH}-$. So-called spaghetti plots of these observations, with LOESS curves fitted to each group separately, are shown in 


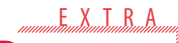

Dementia

and Geriatric

Cognitive Disorders

Fig. 4. Box plot of CDR-SB scores from baseline (BL) to 4-year follow-up (FU4). Light grey: patients with $\mathrm{OH}$ at each examination. Dark grey: patients without $\mathrm{OH}$ at each examination.

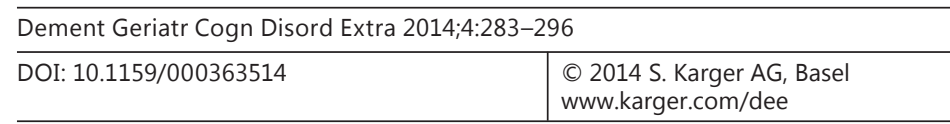

Soennesyn et al.: Persistence and Prognostic Implications of Orthostatic Hypotension in Older Individuals with Mild-to-Moderate Dementia

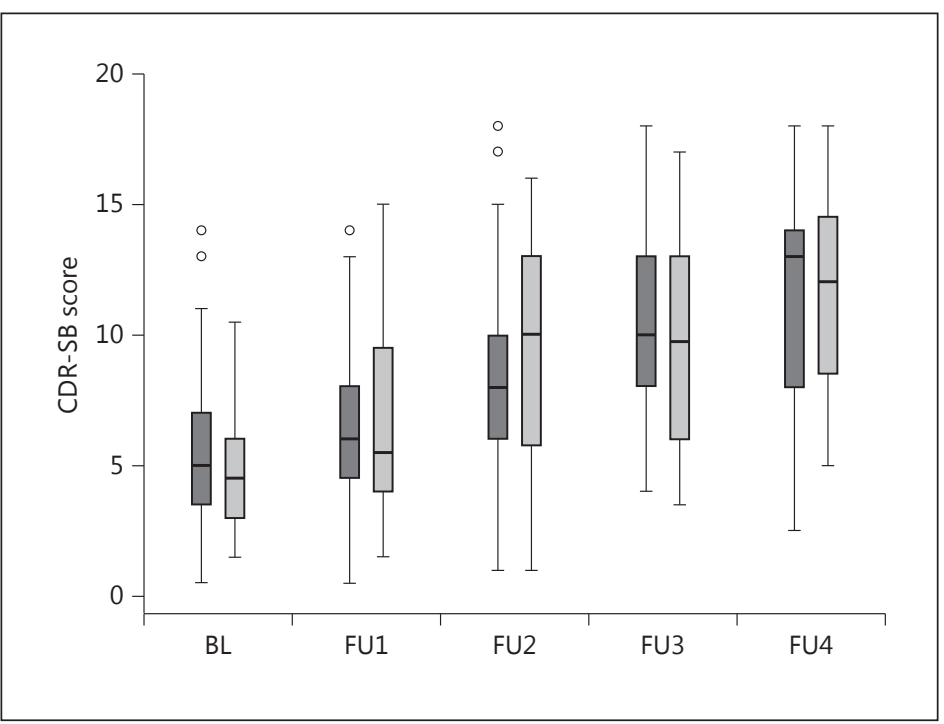

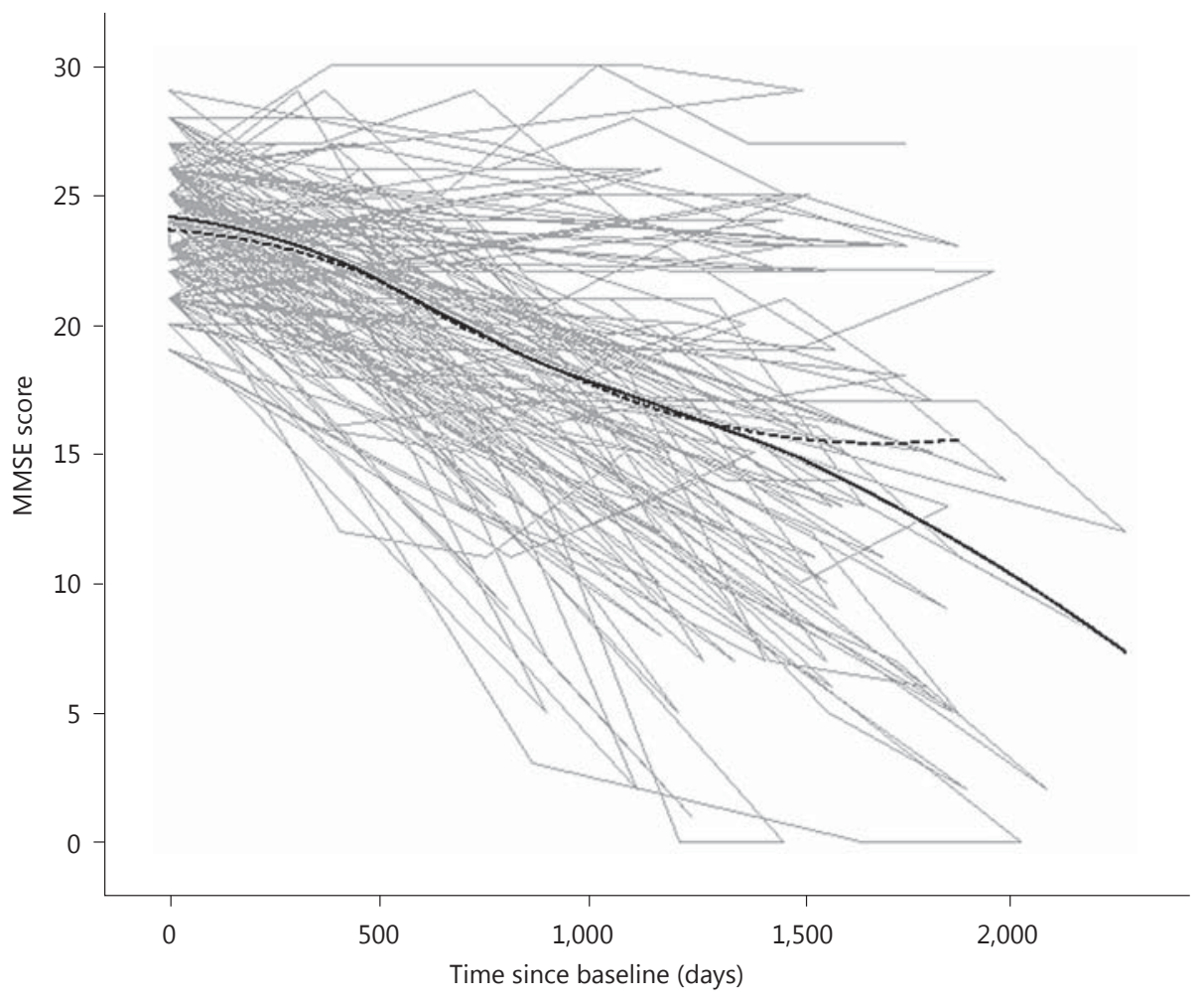

Fig. 5. Course of MMSE scores for 86 patients having either persistent $\mathrm{OH}(\mathrm{OH}+)$ or never $\mathrm{OH}(\mathrm{OH}-)$ at baseline and the 1-year follow-up. Observed individual curves (light grey) as well as fitted LOESS curves for the mean responses for the $\mathrm{OH}$ - group (solid black line) and for the $\mathrm{OH}+$ group (dashed black line). 


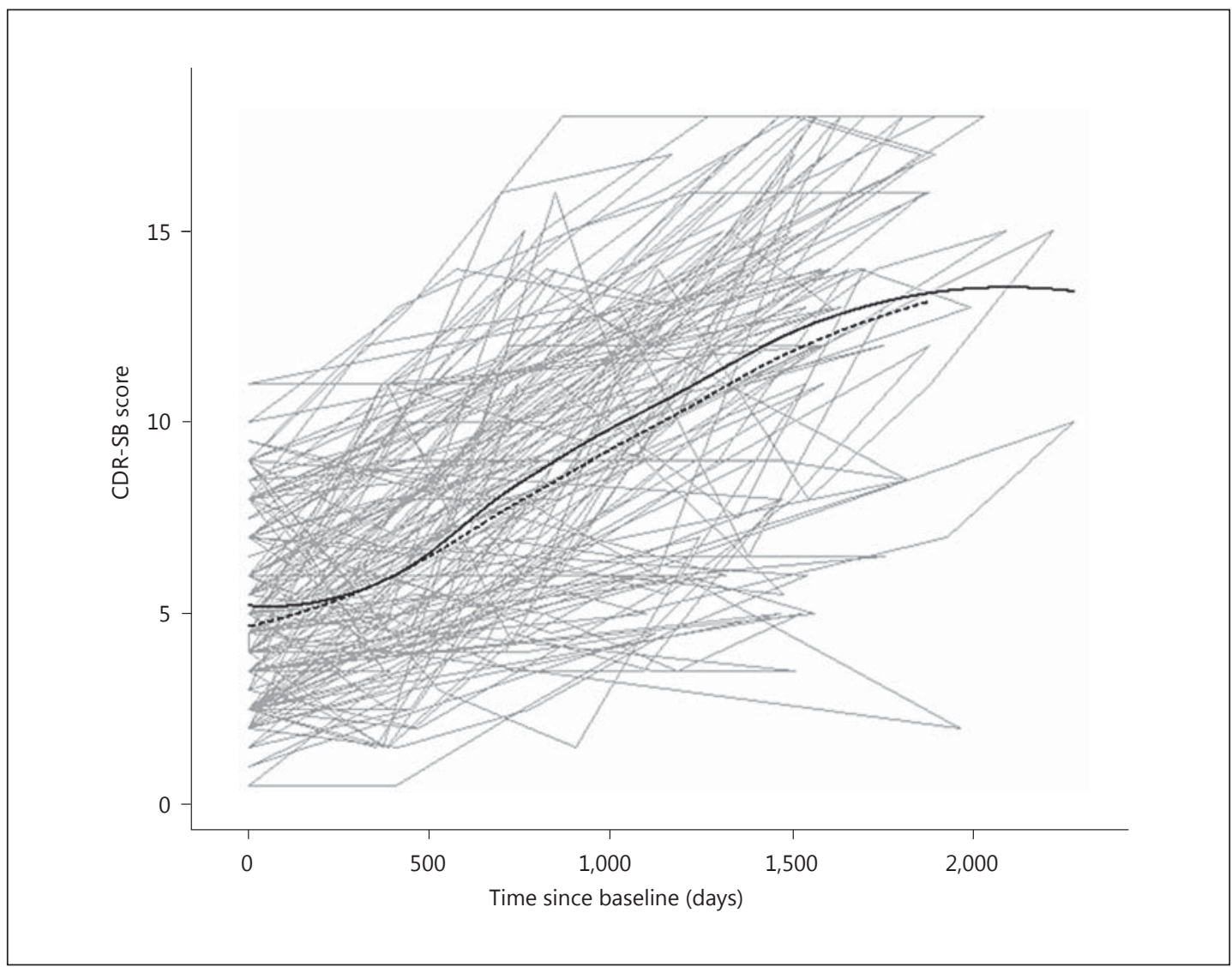

Fig. 6. Course of CDR-SB scores for 86 patients having either persistent $\mathrm{OH}(\mathrm{OH}+)$ or never $\mathrm{OH}(\mathrm{OH}-)$ at baseline and the 1-year follow-up. Observed individual curves (light grey) as well as fitted LOESS curves for the mean responses for the $\mathrm{OH}$ - group (solid black line) and for the $\mathrm{OH}+$ group (dashed black line).

figures 5 and 6, respectively. These plots seem to imply that $\mathrm{OH}$ status has little impact on the course of CDR-SB and MMSE scores, as the LOESS curves are very similar for the $\mathrm{OH}-$ and the $\mathrm{OH}+$ groups. The differences are found mostly towards the end, where the data are increasingly scarce. Using GEE modelling (table 3 ), we found that there was indeed no evidence of a differential longitudinal development in CDR-SB scores according to $\mathrm{OH}$ status ( $p>0.76$ for the interaction effect in all models); furthermore, there was no evidence of a difference in scores at baseline ( $p>0.42)$. With regard to MMSE scores (table 4), some differences at baseline showed up in the adjusted estimates (models 3 and 4, p $<0.005$ ); however, we found little evidence of a difference in the slopes of the curves (all $p \geq 0.24$ ).

Using the package joineR, we fitted joint models in which the longitudinal and the survival outcomes were linked through common random effects. For CDR-SB scores (table 3), the results from joint modelling were similar to the GEE results, with very small and solidly nonsignificant interaction effects $(\mathrm{OH}+/$ time $)$ and with estimated baseline differences always smaller than 0.5 (in favour of the $\mathrm{OH}+$ group; not statistically significant, $\mathrm{p} \geq 0.35$ ). For MMSE scores (table 4), the evidence of a differential longitudinal development increased somewhat ( $p$ values from 0.17 to 0.22 ); however, the statistically significant differences at baseline disappeared (though still indicated with the lowest $p$ value of 0.063 ). 
Soennesyn et al.: Persistence and Prognostic Implications of Orthostatic Hypotension in Older Individuals with Mild-to-Moderate Dementia

Table 3. GEE and joint models for the longitudinal course of CDR-SB scores

\begin{tabular}{|c|c|c|c|c|c|c|}
\hline & \multicolumn{2}{|l|}{ Persistent $\mathrm{OH}$} & \multicolumn{2}{|l|}{ Time } & \multicolumn{2}{|l|}{ Interaction } \\
\hline & $\beta(95 \% \mathrm{CI})$ & $\mathrm{p}$ & $\beta(95 \% \mathrm{CI})$ & $\mathrm{p}$ & $\beta(95 \% \mathrm{CI})$ & $\mathrm{p}$ \\
\hline \multicolumn{7}{|l|}{$G E E$} \\
\hline Model $1^{\mathrm{a}}$ & $-0.36(-1.23$ to 0.52$)$ & 0.423 & $1.70(1.46-1.95)$ & $<0.001$ & $0.07(-0.36$ to 0.49$)$ & 0.762 \\
\hline Model $2^{b}$ & $-0.36(-1.26$ to 0.55$)$ & 0.442 & $1.71(1.46-1.96)$ & $<0.001$ & $0.05(-0.37$ to 0.47$)$ & 0.817 \\
\hline Model $3^{c}$ & $-0.46(-1.79$ to 0.88$)$ & 0.505 & $1.71(1.45-1.97)$ & $<0.001$ & $0.05(-0.38$ to 0.48$)$ & 0.830 \\
\hline Model $4^{\mathrm{d}}$ & $-0.40(-1.67$ to 0.87$)$ & 0.535 & $1.72(1.46-1.98)$ & $<0.001$ & $-0.01(-0.43$ to 0.41$)$ & 0.956 \\
\hline \multicolumn{7}{|l|}{ Joint } \\
\hline Model $1^{\mathrm{a}}$ & $-0.43(-1.60$ to 0.59$)$ & 0.361 & $1.75(1.42-2.04)$ & $<0.001$ & $0.06(-0.43$ to 0.64$)$ & 0.670 \\
\hline Model $2^{b}$ & $-0.43(-1.48$ to 0.55$)$ & 0.350 & $1.75(1.46-2.03)$ & $<0.001$ & $0.06(-0.40$ to 0.53$)$ & 0.778 \\
\hline Model $3^{c}$ & $-0.27(-2.36$ to 1.52$)$ & 0.656 & $1.82(1.48-2.14)$ & $<0.001$ & $0.01(-0.45$ to 0.53$)$ & 0.870 \\
\hline Model $4^{\mathrm{d}}$ & $-0.35(-1.97$ to 1.14$)$ & 0.605 & $1.84(1.48-2.16)$ & $<0.001$ & $-0.04(-0.53$ to 0.53$)$ & 0.989 \\
\hline
\end{tabular}

a 'Unadjusted' $(n=86) .{ }^{b}$ Adjusted for age and sex $(n=86) .{ }^{c}$ Adjusted for all candidate covariates $(n=78)$. ${ }^{\mathrm{d}}$ Adjusted for age, sex, centre, smoking, antidementia medication, cardiovascular disease, education, and MMSE score at baseline $(n=79)$.

Table 4. GEE and joint models for the longitudinal course of MMSE scores

\begin{tabular}{|c|c|c|c|c|c|c|}
\hline & \multicolumn{2}{|l|}{ Persistent $\mathrm{OH}$} & \multicolumn{2}{|l|}{ Time } & \multicolumn{2}{|l|}{ Interaction } \\
\hline & $\beta(95 \% \mathrm{CI})$ & $\mathrm{p}$ & $\beta(95 \% \mathrm{CI})$ & $\mathrm{p}$ & $\beta(95 \% \mathrm{CI})$ & $\mathrm{p}$ \\
\hline \multicolumn{7}{|l|}{$G E E$} \\
\hline Model $1^{\mathrm{a}}$ & $-0.49(-1.38$ to 0.39$)$ & 0.274 & $-2.41(-2.87$ to -1.96$)$ & $<0.001$ & $0.36(-0.45$ to 1.17$)$ & 0.383 \\
\hline Model $2^{b}$ & $-0.56(-1.52$ to 0.40$)$ & 0.254 & $-2.41(-2.85$ to -1.96$)$ & $<0.001$ & $0.37(-0.44$ to 1.17$)$ & 0.370 \\
\hline Model 3c & $-2.08(-3.47$ to -0.68$)$ & 0.004 & $-2.57(-3.02$ to -2.12$)$ & $<0.001$ & $0.46(-0.31$ to 1.22$)$ & 0.240 \\
\hline Model $4^{\mathrm{d}}$ & $-1.89(-3.08$ to -0.69$)$ & 0.002 & $-2.45(-2.86$ to -2.02$)$ & $<0.001$ & $0.34(-0.41$ to 1.09$)$ & 0.377 \\
\hline \multicolumn{7}{|l|}{ Joint } \\
\hline Model $1^{\mathrm{a}}$ & $-0.69(-1.77$ to 0.34$)$ & 0.181 & $-2.72(-3.25$ to -2.15$)$ & $<0.001$ & $0.55(-0.36$ to 1.46$)$ & 0.214 \\
\hline Model $2^{\mathrm{b}}$ & $-0.58(-1.75$ to 0.58$)$ & 0.313 & $-2.68(-3.13$ to -2.22$)$ & $<0.001$ & $0.53(-0.35$ to 1.45$)$ & 0.223 \\
\hline Model $3^{c}$ & $-1.08(-2.27$ to 0.13$)$ & 0.063 & $-2.81(-3.40$ to -2.18$)$ & $<0.001$ & $0.72(-0.28$ to 1.67$)$ & 0.172 \\
\hline Model $4^{\mathrm{d}}$ & $-0.70(-1.71$ to 0.22$)$ & 0.117 & $-2.74(-3.25$ to -2.16$)$ & $<0.001$ & $0.60(-0.38$ to 1.58$)$ & 0.219 \\
\hline
\end{tabular}

a 'Unadjusted' $(\mathrm{n}=86) .{ }^{\mathrm{b}}$ Adjusted for age and sex $(\mathrm{n}=86) .{ }^{\mathrm{c}}$ Adjusted for all candidate covariates $(\mathrm{n}=76)$. ${ }^{\mathrm{d}}$ Adjusted for age, sex, centre, CDR-SB score (at baseline), and CIRS score ( $\left.\mathrm{n}=82\right)$.

\section{Discussion}

This is one of a few studies exploring the longitudinal course and clinical predictive power of $\mathrm{OH}$ in older individuals with dementia. The point prevalence of $\mathrm{OH}$ was $44 \%$ at baseline and remained in the range of $30-45 \%$ during the study period. The persistence of $\mathrm{OH}$ from one year to the next was around $50 \%$, although only about $10 \%$ of the patients had $\mathrm{OH}$ at 3 successive examinations. One might perhaps expect an increasing $\mathrm{OH}$ prevalence over time due to ageing and associated baroreflex impairments $[4,50]$. Such an increase was not observed, however. This could be due to individuals with $\mathrm{OH}$ having a higher mortality rate [17], thus keeping the prevalence relatively constant, or due to the moderate length of our follow-up period. An alternative explanation is, as indeed our findings suggest, that the prev- 
alence of $\mathrm{OH}$ in dementia is rather constant, even as the dementing disease progresses. It is possible that $\mathrm{OH}$ is caused by changes occurring early in the disease course. However, this might differ between various types of dementia. Due to the incompleteness of the relevant data, and also the relatively few patients in the non-AD groups, we were not able to fully explore this question. The rather constant prevalence of $\mathrm{OH}$ conceivably also could be due to adjustments of medications potentially contributing to $\mathrm{OH}$, in response to a diagnosis of $\mathrm{OH}$, or for other reasons. The lack of relevant data precluded adjusting for this potential contributing factor. Dehydration, which may be a prevalent problem in nursing home residents [51], might possibly also have affected the observed prevalence of $\mathrm{OH}$, as more of the patients became nursing home residents due to progression of their dementia. Nevertheless, no increase in $\mathrm{OH}$ prevalence was observed.

In two cross-sectional studies including patients with mild and moderate dementia, point prevalence values similar to ours were found for $\mathrm{OH}[6,9]$ in the $\mathrm{AD}$ and $\mathrm{VaD}$ groups, but higher values in the LBD group, which also appeared to have a more prolonged period of $\mathrm{OH}$. These studies employed a longer standing $\mathrm{OH}$ measurement period with more measurement points [52] and more precise measurement devices than our study.

Regarding the longitudinal functional implications of $\mathrm{OH}$, our results, which are in line with those of a previous study [15], did not confirm the hypothesis that having persistent $\mathrm{OH}$ predicts a more rapid cognitive and functional decline in these patients, at least not with regard to function as measured with the CDR-SB. However, with respect to cognitive function as measured with the MMSE, there seems to be some weak evidence of an association with OH status. Notably, both MMSE scores and CDR-SB scores are rather unspecific outcome measures, and the employment of more specific and sensitive instruments might have produced different results. Still, with respect to the MMSE, a study of cognitive functions in patients with neurogenic $\mathrm{OH}$ found $\mathrm{OH}$ to be associated with impairment of global cognitive functioning as well as more specific tasks, mainly concerning executive functions [53]. Furthermore, both of these instruments have been used to follow the course of AD, DLB, and $\mathrm{VaD}$ in previous studies [54-56]. Although the neuropsychological profiles of AD and DLB are different [57], the longitudinal decline in MMSE scores has been shown to be equivalent [55].

The course towards the end of the follow-up period of both the MMSE and the CDR-SB scores raises suspicion with regard to a 'healthy survivor' effect, which might possibly influence the results in the 'persistent' $\mathrm{OH}$ and the 'never' $\mathrm{OH}$ groups differently. An approach to account for biases because of informative dropout due to death is to model the longitudinal and the survival responses jointly [45-47]. Even though there do not seem to be any substantial differences in mortality rates between the two groups, there may be differences as to who died. In the joint models, we found significant link parameters, implying that there were latent associations between the longitudinal and the survival processes. Even so, these extended analyses did not change our conclusions.

In contrast to a previous study including patients with LBD only [17], we found no association between persistent $\mathrm{OH}$ and survival. Notably, our study differs from this study with respect to both the types of dementia involved and the definition of persistent $\mathrm{OH}$.

Our study has some limitations. These include the relative lack of standardisation of the $\mathrm{OH}$ measurements, with only 1 standing $\mathrm{OH}$ measurement in most cases within a period limited to $3 \mathrm{~min}$, a sizeable proportion of $\mathrm{OH}$ measurements starting from the sitting instead of the supine position, and the lack of a predetermined preceding period of rest. Furthermore, manual sphygmomanometers were employed instead of more precise devices, and the clinicians performing the measurements did not receive any particular training in $\mathrm{OH}$ measurement prior to the study. These factors may have led to an underestimation of the prevalence of $\mathrm{OH}$ $[52,58]$. 
Soennesyn et al.: Persistence and Prognostic Implications of Orthostatic Hypotension in Older Individuals with Mild-to-Moderate Dementia

A proportion of the patients had missing data at some assessments, which may have resulted in less precise estimates of $\mathrm{OH}$ prevalence. However, except for data missing due to death, these missing data were random, and thus there was probably no systematic selection bias, suggesting that these factors did not systematically influence the findings. Still, our results should be interpreted with some caution.

We realise that the study may not have the statistical power needed for us to discover potential small prognostic correlates of $\mathrm{OH}$, and that some of the models used may have been over-parameterised considering the sample size. The confidence intervals for the effects of OH on MMSE and CDR-SB scores are all quite wide, reflecting the limited amount of data on a subject of substantial complexity. For the MMSE, plausible values for yearly change for the $\mathrm{OH}+$ group versus the $\mathrm{OH}$ - group range from about -0.4 to +1.5 ; for the CDR-SB, every value between -0.5 and +0.5 is plausible. The point estimates, however, were relatively consistent in all the models and point towards no clinically relevant effect of having persistent $\mathrm{OH}$ either on survival or on the baseline level or longitudinal course of CDR-SB scores. As stated above, with regard to the longitudinal course of MMSE scores, there seems to be some weak evidence of an association with $\mathrm{OH}$ status, but this clearly should be explored in a larger sample.

The strengths of this study include its prospective design, the relatively large sample of participants recruited from various centres, the inclusion of all common dementia subtypes, its comprehensive evaluation programme, the availability of data on a number of established or potential prognostic factors, and the comparatively long follow-up period.

In conclusion, $\mathrm{OH}$ was moderately prevalent and persistent over time in a sample of older individuals initially having mild dementia. Our results did not confirm the hypothesis that persistent $\mathrm{OH}$ would predict a more rapid cognitive and functional decline in these patients or shorter survival. However, being a rather common and potentially treatable condition, and due to its association with falls, $\mathrm{OH}$ should be actively looked for in patients with dementia. Future studies should include a larger sample and use more rigorous methods for $\mathrm{OH}$ measurement.

\section{Acknowledgements}

This study was financially supported by grant 911694 from the Western Norway Regional Health Authority.

\section{References}

$\checkmark 1$ Consensus statement on the definition of orthostatic hypotension, pure autonomic failure, and multiple system atrophy. The Consensus Committee of the American Autonomic Society and the American Academy of Neurology. Neurology 1996;46:1470.

-2 Lahrmann H, Cortelli P, Hilz M, Mathias CJ, Struhal W, Tassinari M: EFNS guidelines on the diagnosis and management of orthostatic hypotension. Eur J Neurol 2006;13:930-936.

-3 Task Force for the Diagnosis and Management of Syncope, European Society of Cardiology, European Heart Rhythm Association, Heart Failure Association, Heart Rhythm Society; Moya A, Sutton R, Ammirati F, et al: Guidelines for the diagnosis and management of syncope (version 2009). Eur Heart J 2009;30:2631-2671.

-4 Rutan GH, Hermanson B, Bild DE, Kittner SJ, LaBaw F, Tell GS: Orthostatic hypotension in older adults: the Cardiovascular Health Study. CHS Collaborative Research Group. Hypertension 1992;19:508-519.

5 Vitiello B, Veith RC, Molchan SE, Martinez RA, Lawlor BA, Radcliffe J, Hill JL, Sunderland T: Autonomic dysfunction in patients with dementia of the Alzheimer type. Biol Psychiatry 1993;34:428-433.

6 Andersson M, Hansson O, Minthon L, Ballard CG, Londos E: The period of hypotension following orthostatic challenge is prolonged in dementia with Lewy bodies. Int J Geriatr Psychiatry 2008;23:192-198.

7 Sonnesyn H, Nilsen DW, Rongve A, Nore S, Ballard C, Tysnes OB, Aarsland D: High prevalence of orthostatic hypotension in mild dementia. Dement Geriatr Cogn Disord 2009;28:307-313. 
8 Lipsitz LA: Orthostatic hypotension in the elderly. N Engl J Med 1989;321:952-957.

9 Allan LM, Ballard CG, Allen J, Murray A, Davidson AW, McKeith IG, Kenny RA: Autonomic dysfunction in dementia. J Neurol Neurosurg Psychiatry 2007;78:671-677.

10 Kamaruzzaman S, Watt H, Carson C, Ebrahim S: The association between orthostatic hypotension and medication use in the British Women's Heart and Health Study. Age Ageing 2010;39:51-56.

11 Allan LM, Ballard CG, Rowan EN, Kenny RA: Incidence and prediction of falls in dementia: a prospective study in older people. PLoS One 2009;4:e5521.

12 Verwoert GC, Mattace-Raso FU, Hofman A, Heeringa J, Stricker BH, Breteler MM, Witteman JC: Orthostatic hypotension and risk of cardiovascular disease in elderly people: the Rotterdam Study. J Am Geriatr Soc 2008; 56:1816-1820.

13 Matsubayashi K, Okumiya K, Wada T, Osaki Y, Fujisawa M, Doi Y, Ozawa T: Postural dysregulation in systolic blood pressure is associated with worsened scoring on neurobehavioral function tests and leukoaraiosis in the older elderly living in a community. Stroke 1997;28:2169-2173.

14 Mehrabian S, Duron E, Labouree F, Rollot F, Bune A, Traykov L, Hanon O: Relationship between orthostatic hypotension and cognitive impairment in the elderly. J Neurol Sci 2010;299:45-48.

15 Viramo P, Luukinen H, Koski K, Laippala P, Sulkava R, Kivela SL: Orthostatic hypotension and cognitive decline in older people. J Am Geriatr Soc 1999;47:600-604.

16 Allan L, McKeith I, Ballard C, Kenny RA: The prevalence of autonomic symptoms in dementia and their association with physical activity, activities of daily living and quality of life. Dement Geriatr Cogn Disord 2006;22: 230-237.

17 Stubendorff K, Aarsland D, Minthon L, Londos E: The impact of autonomic dysfunction on survival in patients with dementia with Lewy bodies and Parkinson's disease with dementia. PLoS One 2012;7:e45451.

18 Figueroa JJ, Basford JR, Low PA: Preventing and treating orthostatic hypotension: as easy as A, B, C. Cleve Clin J Med 2010;77:298-306.

19 Lampela P, Lavikainen P, Huupponen R, Leskinen E, Hartikainen S: Comprehensive geriatric assessment decreases prevalence of orthostatic hypotension in older persons. Scand J Public Health 2013;41:351-358.

-20 Bengtsson-Lindberg M, Larsson V, Minthon L, Wattmo C, Londos E: Lack of orthostatic symptoms in dementia patients with orthostatic hypotension. Clin Auton Res 2014, Epub ahead of print.

21 Lipsitz LA, Storch HA, Minaker KL, Rowe JW: Intra-individual variability in postural blood pressure in the elderly. Clin Sci 1985;69:337-341.

22 Ward C, Kenny RA: Reproducibility of orthostatic hypotension in symptomatic elderly. Am J Med 1996;100: 418-422.

23 Vanhanen H, Thijs L, Birkenhager W, Bulpitt C, Tilvis R, Sarti C, Tuomilehto J, Staessen JA: Prevalence and persistency of orthostatic blood pressure fall in older patients with isolated systolic hypertension. Syst-Eur Investigators. J Hum Hypertens 1996;10:607-612.

24 Weiss A, Grossman E, Beloosesky Y, Grinblat J: Orthostatic hypotension in acute geriatric ward: is it a consistent finding? Arch Intern Med 2002;162:2369-2374.

25 Gabbett TJ, Gass GC: Reliability of orthostatic responses in healthy men aged between 65 and 75 years. Exp Physiol 2005;90:587-592.

26 Naschitz JE, Rosner I: Orthostatic hypotension: framework of the syndrome. Postgrad Med J 2007;83:568574.

27 American Psychiatric Association: Diagnostic and Statistical Manual of Mental Disorders: DSM-IV. Washington, American Psychiatric Association, 1994.

28 Folstein MF, Folstein SE, McHugh PR: 'Mini-mental state': a practical method for grading the cognitive state of patients for the clinician. J Psychiatr Res 1975;12:189-198.

-29 Aarsland D, Rongve A, Nore SP, Skogseth R, Skulstad S, Ehrt U, Hoprekstad D, Ballard C: Frequency and case identification of dementia with Lewy bodies using the revised consensus criteria. Dement Geriatr Cogn Disord 2008;26:445-452.

-30 Soennesyn H, Oppedal K, Greve OJ, Fritze F, Auestad BH, Nore SP, Beyer MK, Aarsland D: White matter hyperintensities and the course of depressive symptoms in elderly people with mild dementia. Dement Geriatr Cogn Disord Extra 2012;2:97-111.

-31 McKhann G, Drachman D, Folstein M, Katzman R, Price D, Stadlan EM: Clinical diagnosis of Alzheimer's disease: report of the NINCDS-ADRDA Work Group under the auspices of Department of Health and Human Services Task Force on Alzheimer's Disease. Neurology 1984;34:939-944.

32 McKeith IG, Dickson DW, Lowe J, et al; Consortium on DLB: Diagnosis and management of dementia with Lewy bodies: third report of the DLB Consortium. Neurology 2005;65:1863-1872.

33 Emre M, Aarsland D, Brown R, Burn DJ, Duyckaerts C, Mizuno Y, Broe GA, Cummings J, Dickson DW, Gauthier S, Goldman J, Goetz C, Korczyn A, Lees A, Levy R, Litvan I, McKeith I, Olanow W, Poewe W, Quinn N, Sampaio C, Tolosa E, Dubois B: Clinical diagnostic criteria for dementia associated with Parkinson's disease. Mov Disord 2007;22:1689-1707, quiz 1837.

-34 Roman GC, Tatemichi TK, Erkinjuntti T, Cummings JL, Masdeu JC, Garcia JH, Amaducci L, Orgogozo JM, Brun A, Hofman A, et al: Vascular dementia: diagnostic criteria for research studies. Report of the NINDS-AIREN International Workshop. Neurology 1993;43:250-260.

35 Clinical and neuropathological criteria for frontotemporal dementia. The Lund and Manchester Groups. J Neurol Neurosurg Psychiatry 1994;57:416-418. 
-36 Aarsland D, Ballard CG, Halliday G: Are Parkinson's disease with dementia and dementia with Lewy bodies the same entity? J Geriatr Psychiatry Neurol 2004;17:137-145.

37 Hughes CP, Berg L, Danziger WL, Coben LA, Martin RL: A new clinical scale for the staging of dementia. Br J Psychiatry 1982;140:566-572.

-38 O’Bryant SE, Waring SC, Cullum CM, Hall J, Lacritz L, Massman PJ, Lupo PJ, Reisch JS, Doody R; Texas Alzheimer's Research Consortium: Staging dementia using Clinical Dementia Rating Scale Sum of Boxes scores: a Texas Alzheimer's Research Consortium study. Arch Neurol 2008;65:1091-1095.

39 Coley N, Andrieu S, Jaros M, Weiner M, Cedarbaum J, Vellas B: Suitability of the Clinical Dementia Rating-Sum of Boxes as a single primary endpoint for Alzheimer's disease trials. Alzheimers Dement 2011;7:602-610e2.

40 Conwell Y, Forbes NT, Cox C, Caine ED: Validation of a measure of physical illness burden at autopsy: the Cumulative Illness Rating Scale. J Am Geriatr Soc 1993;41:38-41.

41 Montgomery SA, Åsberg M: A new depression scale designed to be sensitive to change. Br J Psychiatry 1979; 134:382-389.

42 Muller-Thomsen T, Arlt S, Mann U, Mass R, Ganzer S: Detecting depression in Alzheimer's disease: evaluation of four different scales. Arch Clin Neuropsychol 2005;20:271-276.

43 Scheltens P, Barkhof F, Leys D, Pruvo JP, Nauta JJ, Vermersch P, Steinling M, Valk J: A semiquantative rating scale for the assessment of signal hyperintensities on magnetic resonance imaging. J Neurol Sci 1993;114: 7-12.

-44 Richard E, Moll van Charante EP, van Gool WA: Vascular risk factors as treatment target to prevent cognitive decline. J Alzheimers Dis 2012;32:733-740.

45 Murphy TE, Han L, Allore HG, Peduzzi PN, Gill TM, Lin H: Treatment of death in the analysis of longitudinal studies of gerontological outcomes. J Gerontol A Biol Sci Med Sci 2011;66:109-114.

-46 Henderson R, Diggle P, Dobson A: Joint modelling of longitudinal measurements and event time data. Biostatistics 2000;1:465-480.

47 Philipson P, Sousa I, Diggle PJ, Williamson P, Kolamunnage-Dona R, Henderson R: joineR: joint modelling of repeated measurements and time-to-event data. 2012. http://cran.r-project.org/web/packages/joineR/ index.html.

48 Akaike H: A new look at the statistical model identification. IEEE Trans Automat Contr 1974;19:716-723.

49 Efron B, Tibshirani RJ: An Introduction to the Bootstrap. London, Chapman \& Hall, 1993.

50 Monahan KD: Effect of aging on baroreflex function in humans. Am J Physiol Regul Integr Comp Physiol 2007; 293:R3-R12.

51 Wu SJ, Wang HH, Yeh SH, Wang YH, Yang YM: Hydration status of nursing home residents in Taiwan: a crosssectional study. J Adv Nurs 2011;67:583-590.

-52 Passant U, Warkentin S, Gustafson L: Orthostatic hypotension and low blood pressure in organic dementia: a study of prevalence and related clinical characteristics. Int J Geriatr Psychiatry 1997;12:395-403.

53 Poda R, Guaraldi P, Solieri L, Calandra-Buonaura G, Marano G, Gallassi R, Cortelli P: Standing worsens cognitive functions in patients with neurogenic orthostatic hypotension. Neurol Sci 2012;33:469-473.

54 Ballard C, O’Brien J, Morris CM, Barber R, Swann A, Neill D, McKeith I: The progression of cognitive impairment in dementia with Lewy bodies, vascular dementia and Alzheimer's disease. Int J Geriatr Psychiatry 2001;16: 499-503.

55 Hanyu H, Sato T, Hirao K, Kanetaka H, Sakurai H, Iwamoto T: Differences in clinical course between dementia with Lewy bodies and Alzheimer's disease. Eur J Neurol 2009;16:212-217.

56 Aguera-Ortiz L, Frank-Garcia A, Gil P, Moreno A; 5E Study Group: Clinical progression of moderate-to-severe Alzheimer's disease and caregiver burden: a 12-month multicenter prospective observational study. Int Psychogeriatr 2010;22:1265-1279.

57 Oda H, Yamamoto Y, Maeda K: The neuropsychological profile in dementia with Lewy bodies and Alzheimer's disease. Int J Geriatr Psychiatry 2009;24:125-131.

58 Cooke J, Carew S, O'Connor M, Costelloe A, Sheehy T, Lyons D: Sitting and standing blood pressure measurements are not accurate for the diagnosis of orthostatic hypotension. QJM 2009;102:335-339. 